\title{
The Effect of Ambient Air Pollution on Severity of COVID-19: Hospitalisation and Death
}

\author{
Saeed Yari ${ }^{1,2}$, Hanns Moshammer ${ }^{3,4}$
}

${ }^{1}$ School of Health Science, Shahid Beheshti University of Medical Sciences, Tehran, Iran. ${ }^{2}$ Instructor, Occupational Health Engineering, Department of Occupational Health Engineering, Neyshabur University of Medical Sciences, Neyshabur, Iran. ${ }^{3}$ Department of Environmental Health, Center for Public Health, Medical University of Vienna, Austria. ${ }^{4}$ Medical University of Karakalpakstan, Department of Hygiene, Nukus, Uzbekistan.

Asian Pac Environ Cancer, 3 (1), 15-16

The advent of a new Corona virus, SARS-CoVi-2, causing COVID-19, which first began in Wuhan, China, and then spread worldwide, has created a global public health crisis [1]. The sudden and far-reaching pandemic has raised many immediate questions. A very important goal of public health is to identify environmental factors that affect the spread and severity of the disease. Air pollution is one of the most well-known causes of long-term inflammation, which ultimately leads to increased immune system hyperactivity [2]. Air pollution is one of the leading causes of death and is estimated to play a role in nearly 5 million premature deaths worldwide in 2017 alone. Numerous scientific studies have linked air pollution to a variety of health concerns, including premature death in patients with heart or lung disease, non-fatal heart attacks, irregular heartbeats, and severe asthma [3]. Acute and chronic exposure to chemicals, such as air pollutants, can lead to an increase in diseases such as cancer and allergies, and can exacerbate major respiratory disorders and infections in children and adults [4]. On the other hand, severe COVID-19 infection is characterized by a high inflammatory load and can cause viral pneumonia with additional manifestations and extrapulmonary complications, including acute respiratory distress syndrome (ARDS) [5-6]. Patients with severe COVID-19 disease can suffer from respiratory and other vital systems failure that can eventually lead to death [7-8]. Particulate air pollution exposure is associated with increased risk of severe outcomes in patients with certain infectious respiratory diseases, including influenza, pneumonia, and SARS [5]. Therefore, prolonged exposure to environmental pollution with a negative impact on the functioning of the respiratory and cardiovascular systems carries the risk of severe COVID-19 symptoms and death. Thus, chronic exposure to particulate air pollution might render the respiratory tract more vulnerable to infection by
Submission Date: 05/09/2020Ａcceptance Date: 05/14/2020

COVID-19 and also increase the risk of severe outcomes (hospitalization, intensive care, or death) in case of infection. But also, short-term air pollution episodes could interact with the virus either by prolonging the viability of the virus in the environment or by interfering with the local innate immunity of the respiratory mucous membranes [9].

Since the risk of environmental pollution in urban and industrial polluted areas is higher than rural areas, COVID-19 intensity should be higher in urban and crowded areas. On the other hand, acute and chronic exposure of chemical industry workers to occupational pollution can have similar results [4-10]. Therefore, in addition to public health measures to fight COVID-19, measures to prevent non-communicable diseases caused by air pollution should be considered to improve the immune system and create host resistance against COVID-19. Therefore, studies are needed to determine the impact of air pollution (environmental or occupational exposure) on the prevalence of the disease and its severity and mortality. And its results can be used to manage the activities of infected processes and industries and to create appropriate guidelines and rules to control environmental and occupational exposure. General messages in the fight against COVID-19 should also include avoiding toxic substances in order to strengthen the immune system.

Governmental actions all over the world in fighting the spread of the COVID-19 pandemic have been surprisingly swift and strong (e.g. [11]) even though they caused severe interruption of the economy and led to numerous constraints on global trade and production. Measures against air pollution have so far not been observed even in much less intensity although air pollution as a cumulative threat causes a much higher death toll than SARS-CoVi-2. Or, but to name one other example: Climate change is with good reason termed the worst public health crisis of the 21 st century [12]. Fighting climate change would not

Corresponding Author:

Saeed Yari

School of Health Science, Shahid Beheshti University of Medical Sciences, Tehran, Iran. Instructor, Occupational Health Engineering,

Department of Occupational Health Engineering, Neyshabur University of Medical Sciences, Neyshabur, Iran.

Email: smaeedy@gmail.com 
only require national governmental measures but global trust and cooperation between countries, virtues that would have been needed in the current COVID-19 crisis as well but have been lacking so far.

\section{References}

1. Yari S, Moshammer H, Asadi AF. Side Effects of Using Disinfectants to Fight COVID-19. Asian Pacific Journal of Environment and Cancer. 2020;3(1):9-13.

2. Wang D, Hu B, Hu C, Zhu F, Liu X, Zhang J, et al. Clinical characteristics of 138 hospitalized patients with 2019 novel coronavirus-infected pneumonia in Wuhan, China. Jama. 2020;323(11):1061-9.

3. United States Environmental Protection Agency. Integrated Science Assessment (ISA) for Particulate Matter (Final Report, 2019). EPA/600/R-19/188. Washington, DC: US EPA 2019.

4. Yari S, Asadi AF, Jarrahi AM, Nourmohammadi M. CARcinogen EXposure: CAREX. Asian Pacific Journal of Environment and Cancer. 2018;1(1).

5. Wu X, Nethery RC, Sabath BM, Braun D, Dominici F. Exposure to air pollution and COVID-19 mortality in the United States. medRxiv. 2020.

6. Madarsara TJ, Kudakan NA, Yari S, Saeidabadi H. Assessing respiratory exposure to harmful evaporations in a manufacturing company. Asian Pacific Journal of Environment and Cancer. 2019;2(2).

7. Conticini E, Frediani B, Caro D. Can atmospheric pollution be considered a co-factor in extremely high level of SARSCoV-2 lethality in Northern Italy? Environmental Pollution. 2020:114465.

8. Andree BPJ. Incidence of COVID-19 and Connections with Air Pollution Exposure: Evidence from the Netherlands. World Bank Policy Research Working Paper. 2020(9221).

9. Bauer RN, Diaz-Sanchez D, Jaspers I. Effects of air pollutants on innate immunity: the role of Toll-like receptors and nucleotide-binding oligomerization domain-like receptors. Journal of allergy and clinical immunology. 2012;129(1):1424.

10. Yari S, Asadi AF, Nourmohammadi M. Occupational and Environmental Cancer. Asian Pacific Journal of Environment and Cancer. 2018;1(1).

11. Moshammer H, Poteser M, Lemmerer K, Wallner P, Hutter H-P. Time Course of COVID-19 Cases in Austria. International Journal of Environmental Research and Public Health. 2020;17(9):3270.

12. Watts N, Amann M, Arnell N, Ayeb-Karlsson S, Belesova K, Berry H, et al. The 2018 report of the Lancet Countdown on health and climate change: shaping the health of nations for centuries to come. The Lancet. 2018;392(10163):2479-514.

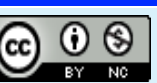

This work is licensed under a Creative Commons AttributionNon Commercial 4.0 International License. 